Supporting information

\title{
Capture and Reversible Storage of Volatile Iodine by Novel Conjugated Microporous Polymers Containing Thiophene Units
}

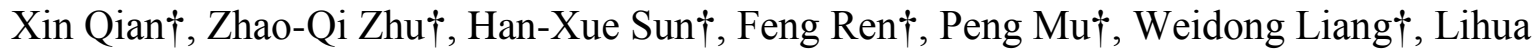
Chen*,, , An Li*, $\dagger$

$\dagger$ College of Petrochemical Technology, Lanzhou University of Technology, Lanzhou 730050, P. R. China

${ }^{\ddagger}$ Experimental Center, Northwest University for Nationalities, Lanzhou 730030, P.R. China

Corresponding Author: An Li†, Lihua Chen $\ddagger$

*†E-mail address: $\underline{\text { lian2010@lut.cn }}$

${ }^{* \pm}$ E-mail address: $\underline{\text { clh@ } @ \text { xbmu.edu.cn }}$

\section{Contents}

- Figure S1: The TGA curves of SCMP-1 and SCMP-2.

- Figure S2: XRD patterns of SCMPs.

- Figure S3: XPS spectrum of SCMP-1 and SCMP-2 after iodine capture. XPS spectrum of $\mathrm{I}_{2}$-loaded SCMP-1 and SCMP-2.

- Table S1: Results from Linear Regression of Adsorption Rate Experiments of SCMP-2

- Table S2: Regression Equation for Langmuir Isotherms of SCMP-2

- Table S3: Regression Equation for Freundlich Isotherms of SCMP-2

- Table S4: Changes of Adsorptions Enthalpy $(\Delta H)$, Gibbs free energy $(\Delta G)$ and Entropy $(\Delta S)$ for SCMP-2 


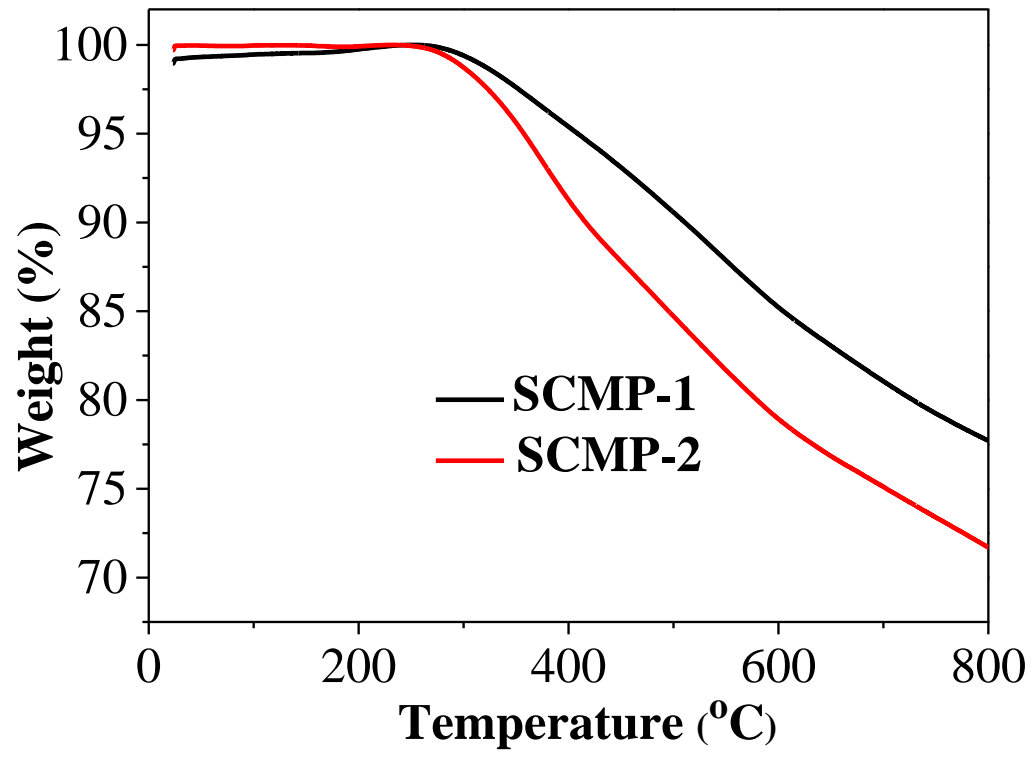

Figure S1. The TGA curves of SCMP-1 and SCMP-2.

The thermal property of SCMP-1 and SCMP-2 are shown in Figure S1. It is obvious that the weight loss of both SCMP-1 and SCMP-2 is lower than $15 \%$ even the temperature reached up to $400{ }^{\circ} \mathrm{C}$, suggesting good thermal stability. 


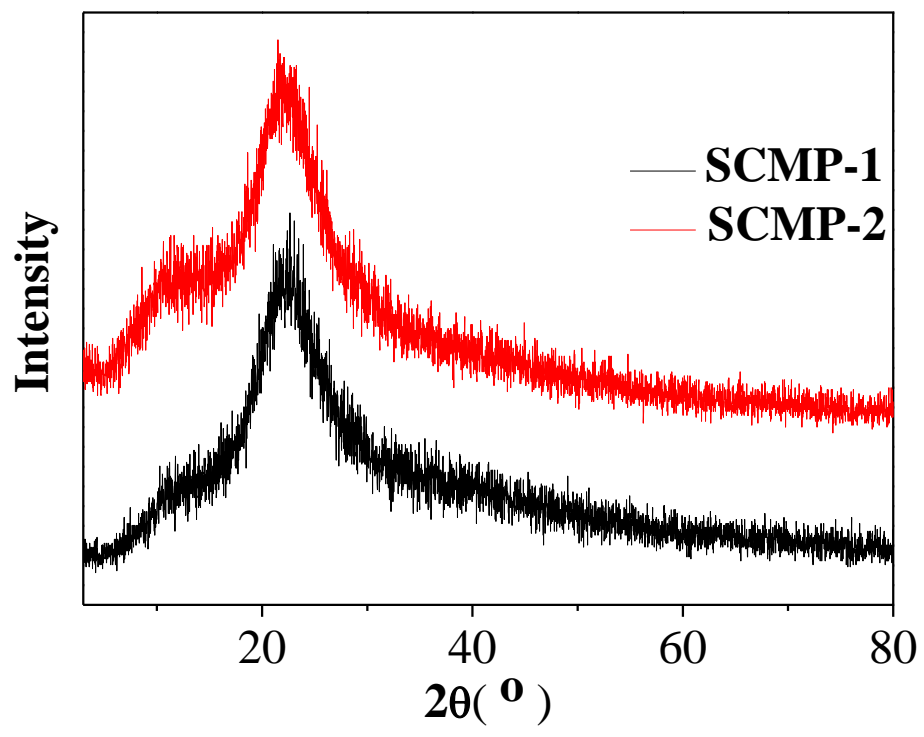

Figure S2. XRD patterns of SCMPs.

The powder X-ray diffraction patterns of SCMP-1 and SCMP-2 are shown in Figure S2. Like most of amorphous polymers, the PXRD patterns of two samples show a characteristic broad peak, indicating they are in amorphous nature. 

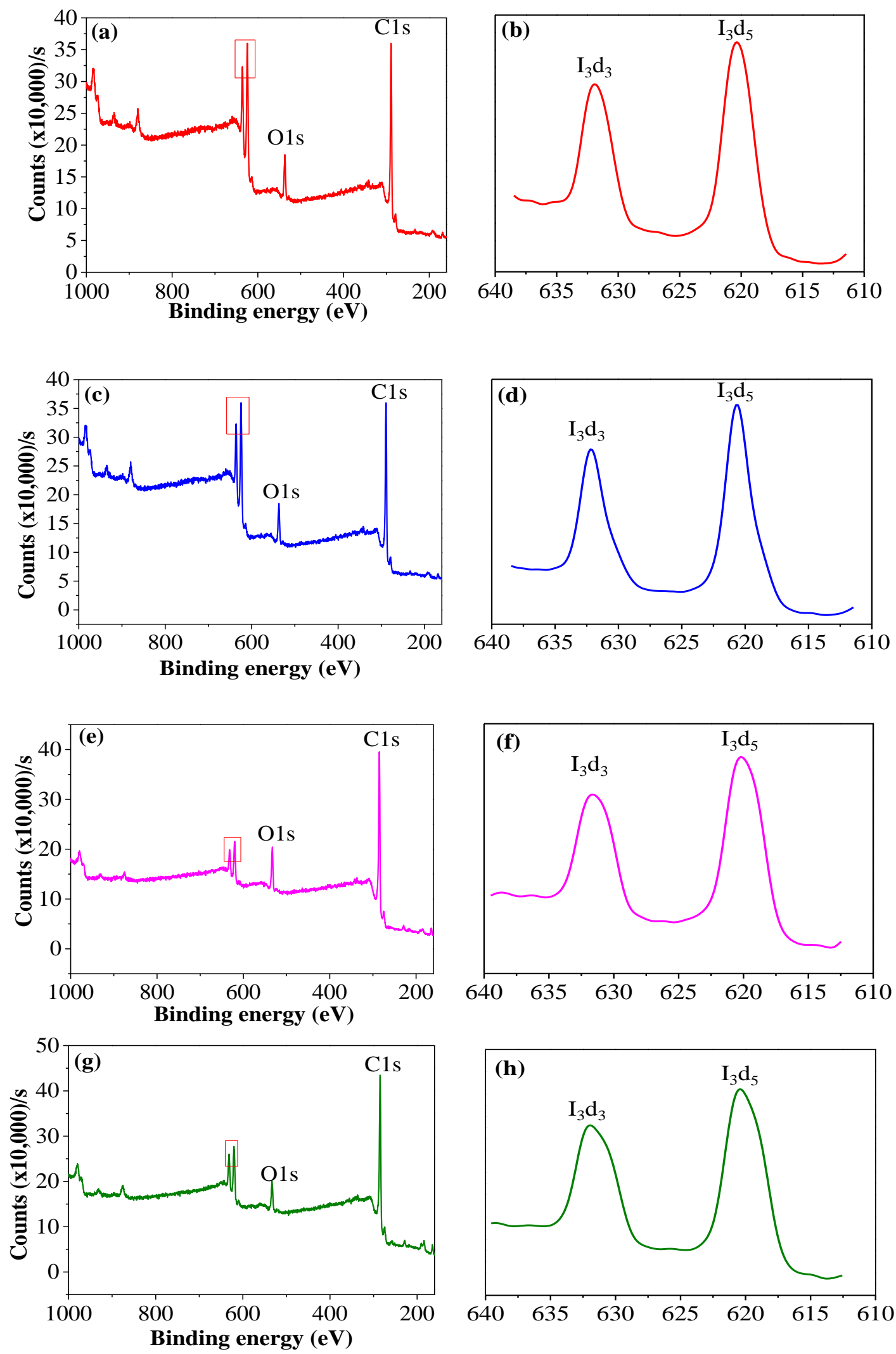
Figure S3. XPS spectrum of SCMP-1 (a), (b) and SCMP-2(c), (d) after iodine capture. XPS spectrum of $\mathrm{I}_{2}$-loaded SCMP-1(e), (f) and SCMP-2(g), (h).

The XPS spectrum of SCMP-1 and SCMP-2 are shown in Figure S3. It is indicated that the trapped iodine with a valance of zero loading on SCMPs, which suggests that the iodine exists as molecule. 
Table S1. Results from Linear Regression of Adsorption Rate Experiments of SCMP-2

\begin{tabular}{ccccccccc}
\hline$\rho_{0}\left(\mathrm{mg} \mathrm{L}^{-1}\right)$ & \multicolumn{2}{c}{$\begin{array}{c}\text { Pseudo-first order } \\
\text { kinetics }\end{array}$} & \multicolumn{2}{c}{$\begin{array}{c}\text { Modified pseudo-first } \\
\text { order kinetics }\end{array}$} & \multicolumn{2}{c}{$\begin{array}{c}\text { Pseudo-second order } \\
\text { kinetics }\end{array}$} & \multicolumn{2}{c}{$\begin{array}{c}\text { Intra-particle diffusion } \\
\text { model }\end{array}$} \\
\hline & $\mathrm{K}_{1}\left(\mathrm{~min}^{-1}\right)$ & $\mathrm{R}^{2}$ & $\mathrm{~K}_{1}\left(\mathrm{~min}^{-1}\right)$ & $\mathrm{R}^{2}$ & $\mathrm{~K}\left(\times 10^{6} \mathrm{~min}^{-1}\right)$ & $\mathrm{R}^{2}$ & $\mathrm{~K} \mathrm{P}\left(\mathrm{mg} \cdot\left(\mathrm{g} \cdot \mathrm{min}^{-1}\right)\right.$ & $\mathrm{R}^{2}$ \\
\hline 250 & 0.00823 & 0.9622 & 0.00719 & 0.9406 & 198.55 & 0.9976 & 5.1821 & 0.9414 \\
200 & 0.00819 & 0.9724 & 0.00706 & 0.9520 & 200.85 & 0.9976 & 4.7902 & 0.9418 \\
150 & 0.00798 & 0.9577 & 0.00658 & 0.9295 & 204.14 & 0.9962 & 4.5183 & 0.9655 \\
100 & 0.00824 & 0.9884 & 0.00671 & 0.9658 & 198.84 & 0.9971 & 3.5767 & 0.9562 \\
50 & 0.00810 & 0.9877 & 0.0065 & 0.9703 & 287.64 & 0.9988 & 2.3595 & 0.9444 \\
\hline
\end{tabular}

The results of four adsorption kinetics models of SCMP-2 are shown in Table S1. Like the results of Table 1, the adsorption data fits well in pseudo-second order kinetics model with good linear correlation coefficient $\left(\mathrm{R}^{2}\right.$ greater than 0.99$)$. It is confirmed that the iodine adsorption process of SCMP-2 was dominated by pseudo-second order kinetics in this work. 
Table S2. Regression Equation for Langmuir Isotherms of SCMP-2

\begin{tabular}{ccccc}
\hline Temperature $(\mathrm{K})$ & Regression equation $\left(\rho_{\mathrm{e}} / \mathrm{q}_{\mathrm{e}}\right)$ & $\mathrm{R}^{2}$ & $\mathrm{q}_{\mathrm{m}}\left(\mathrm{mg} \cdot \mathrm{g}^{-1}\right)$ & $\mathrm{b}\left(\mathrm{L} \cdot \mathrm{mg}^{-1}\right)$ \\
\hline 293 & $0.00402 \rho \mathrm{e}+0.50384$ & 0.99593 & 249.07 & 0.00797 \\
303 & $0.00388 \rho \mathrm{\rho e}+0.46211$ & 0.99512 & 257.73 & 0.00840 \\
313 & $0.00384 \rho \mathrm{ee}+0.39525$ & 0.99729 & 260.28 & 0.00972 \\
\hline
\end{tabular}

The results of Langmuir isotherms of SCMP-2 can be seen in Table S2. Like the results of Table 2, Simulation results have a good linear correlation coefficient $\left(\mathrm{R}^{2}\right.$ greater than 0.99). It is suggesting that Langmuir adsorption isotherm could be well described the iodine adsorption by SCMP-2. 
Table S3. Regression Equation for Freundlich Isotherms of SCMP-2

\begin{tabular}{ccccc}
\hline Temperature $(\mathrm{K})$ & Regression equation $\ln \mathrm{q}_{\mathrm{e}}$ & $\mathrm{R}^{2}$ & $\mathrm{~K}$ & $\mathrm{n}^{-1}$ \\
\hline 293 & $0.50072 \ln \rho_{\mathrm{e}}+2.36405$ & 0.97479 & 10.63 & 0.50072 \\
303 & $0.48217 \ln \rho_{\mathrm{e}}+2.49475$ & 0.97105 & 12.12 & 0.48217 \\
313 & $0.43476 \ln \rho_{\mathrm{e}}+2.78251$ & 0.97185 & 16.16 & 0.43476 \\
\hline
\end{tabular}

The results of Freundlich isotherms of SCMP-2 can be seen in Table S3. Like the results of Table 3, Simulation results have a poor linear correlation coefficient ( $\mathrm{R}^{2}$ less than 0.99$)$. It is suggesting that Freundlich adsorption isotherm could not be well described the iodine adsorption by SCMP-2. 
Table S4. Changes of Adsorptions Enthalpy $(\Delta H)$, Gibbs free energy $(\Delta G)$ and Entropy $(\Delta S)$ for SCMP-2

\begin{tabular}{cccc}
\hline Temperature $(\mathrm{K})$ & $\Delta \mathrm{H}\left(\mathrm{kJ} \cdot \mathrm{mol}^{-1}\right)$ & $\Delta \mathrm{G}\left(\mathrm{kJ} \cdot \mathrm{mol}^{-1}\right)$ & $\Delta \mathrm{S}\left(\mathrm{J} \cdot \mathrm{mol}^{-1} \cdot \mathrm{K}^{-1}\right)$ \\
\hline 293 & 7.53 & -16.85 & 83.23 \\
303 & 7.53 & -17.56 & 82.82 \\
313 & 7.53 & -18.52 & 83.24 \\
\hline
\end{tabular}

The Changes of adsorptions enthalpy $(\Delta \mathrm{H})$, Gibbs free energy $(\Delta \mathrm{G})$ and entropy $(\Delta \mathrm{S})$ for SCMP-2 were shown Table S4.It is confirmed that the adsorption process is endothermal and the adsorption spontaneity gets greater as the temperature rises. 